Article

\title{
Conceptualizing Sustainability Governance Implementation for Infrastructure Delivery Systems in Developing Countries: Success Factors
}

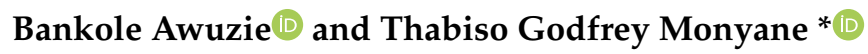 \\ Department of Built Environment, Central University of Technology, Bloemfontein 9301, FS, South Africa; \\ bawuzie@cut.ac.za \\ * Correspondence: tmonyane@cut.ac.za
}

Received: 7 November 2019; Accepted: 18 January 2020; Published: 29 January 2020

check for updates

\begin{abstract}
Infrastructure delivery processes possess the potential to negatively influence sustainability. To curb the incidence of these processes within infrastructure delivery systems, the enthronement of an effective project management and governance framework becomes imperative. This led to the emergence of literature on sustainable project management practice. However, studies seeking to modify existing project governance structures in like manner remain limited. This study contributes to this emerging discourse on the utility of project governance competencies in facilitating sustainable infrastructure delivery. To achieve this objective, this study identifies critical success factors central to the design of effective sustainability governance structures of a typical infrastructure delivery (ID) system with the assistance of a cybernetic system framework-the viable infrastructure delivery systems model (VIDM). Adopting a qualitative multi-case study research design, this study deploys semi-structured interviews for data elicitation through purposively sampled interviewees within the identified cases and a document review. Qualitative content analysis (QCA) was deployed for data analysis. Findings from this study provide success factors for designing effective sustainability governance structures for ID systems. It is expected that the findings from this study will contribute to the emerging discourse concerning sustainability governance of ID systems.
\end{abstract}

Keywords: developing countries; infrastructure delivery; success factors; sustainable development; sustainability governance

\section{Introduction}

The rising demand for adequate infrastructure stock is taking a toll on the natural ecosystem [1-3]. Also, the quick pace of technological transformations experienced in contemporary society places undue pressure on infrastructure client organizations (ICOs) to devise ways to modify or provide the infrastructure which is compatible with such transformations in similar pace. Contributing to the increased investment in infrastructure being witnessed globally is the famed nexus between the availability of infrastructure and economic growth [4]. The latter is reportedly the case with developing countries where efforts to improve the infrastructure stock occupies center stage of contemporary national developmental discourse. However, the aspirations for improved infrastructure stock are confronted with the challenge of delivering these assets in a manner that depicts comprehensive adherence to the sustainable development goals (SDGs). This implies that participants to the delivery of an infrastructure asset must ensure compliance with pre-determined parameters of the three sustainable development dimensions, namely, social, environmental, and economic dimensions, albeit in an integrated manner. Obviously, this will require trade-offs and compromises depending on what dimensions the parties of the infrastructure delivery (ID) system decide to prioritize above the rest. 
Over the years, the construction and infrastructure industry acquired a time-honored reputation for posting devastating effects on the environment and society in different ways [5]. According to extant studies, the construction industry and its products such as critical infrastructure and the built environment made prominent contributions toward undermining the sustainable development agenda [6]. Yet, the industry through its products also provided initiatives for developing sustainable built environments. As such, the challenge is on how to ensure that the industry transforms itself in a way that will only produce the delivery of pro-sustainability products in a sustainable manner. Little wonder the industry is at the forefront of renouncing this reputation through the development of various innovative solutions. One of such solutions is the concept of sustainable construction. According to [7], sustainable construction is predicated on the attainment of economic efficiency, improved environmental performance, and social responsibility across facets like adaptable/flexible building design and construction, enhanced material performance, innovative operations and maintenance schedules, innovative financing models, energy and resource efficiency, increased stakeholder participation and involvement, lifecycle analysis of projects, etc. Also, proponents of another innovative concept (lean construction) insist on its potential to reduce the incidence of non-value-adding activities (waste) within the construction supply chain [8,9]. Most recently, the concept of the circular economy evolved into societal consciousness. This concept deals with effectuating, among other aspects, the principles of industrial synergy, extended producer responsibility, and extended product useful life [10,11]. This concept was applauded as providing a convincing pathway for the attainment of sustainability across different economic sectors. A perfunctory appraisal of these solutions amongst a plethora of others indicates an obsession on processes (technicalities) without regard for the managerial competencies required to drive them to fruition. Also, there is a seeming scarcity of studies seeking to investigate the nature of governance approaches required to facilitate the successful implementation of these processes. The successful implementation of strategic and/or project objectives requires a mix of social and technical aspects.

Literature confirms the emergence of a school of thought soliciting for the integration of sustainable development principles into the project management competencies toolkit within and beyond the realm of construction projects [12,13]. According to proponents of this school, the contemporary project manager needs to possess skillsets beyond that which is expected to attain project management success, i.e., to enable project success instead $[14,15]$. This implies the addition of sustainability and a functionality-based set of performance indicators to the conventional indicators like time, cost, and quality. Whereas studies seeking to advance this course of thinking are on the rise, nothing seems to be going on with regard to the incorporation of sustainability tenets into project governance practice within the realm of construction project delivery, to the best of the authors' knowledge. Although the existence of studies on sustainability governance and/or the governance of sustainable development is noted, such studies do not concern themselves with construction and infrastructure project delivery. Considering how instrumental project governance structures are to project success, it is imperative to investigate the utility of existing project governance approaches in embedding SD tenets across different phases of the project (infrastructure) delivery lifecycle. Whilst this study seeks to contribute to this appraisal, it concerns itself with laying the foundation of such an inquiry through an identification of the critical success factors for designing effective sustainability governance structures of ID systems.

The rest of this paper is structured as follows: a review of state-of-the-art literature on sustainability governance in ID systems and a fully detailed review on the viable infrastructure delivery systems model's (VIDM's) utility for appraising project governance structures within ID systems, justification of the research methods adopted, the presentation and discussion of findings, and a conclusion. 


\section{Literature Review}

\subsection{The Concept of Sustainability Governance in Infrastructure Delivery Systems}

A plethora of views concerning the meaning of governance exist in the literature. Yet, to gain extensive insight into the implication of the concept of sustainability governance, there is a need to define governance and project governance. Significant among the various definitions of the governance concept is the view held by [16], wherein the scholar proposes that the concept of governance be considered from a systems perspective. According to him, such a system comprises the duo of a structure and actor-oriented perspective serving as two disparate modes of governance. Continuing, [16] postulates that the former perspective is concerned with the belief that social systems are self-governing and independent objects which govern themselves through circular, self-referential processes which highlight their identity. However, the actor-oriented perspective views social systems as comprising communications between actors with the actors serving as empirical sub-units. Apparently, this understanding implies that governance involves systems and actors working within the same organizational networks in a self-organizing manner [17].

The views explained previously concerning governance does not differ from those accorded to the concept within the realm of construction and infrastructure project delivery. However, the point of departure lies in the notion that the dyadic actor-actor and/or actor-structure relationships are both characterized by its transactional nature. To buttress this, [18] situates the concept of project governance along two sides of a continuum; firstly, as processes associated with transactions between actors in a project and, secondly, as transactions between institutions at the level of the society. Introducing closer and more specific insight into the concept of project governance, [19] maintain that project governance consists of a series of institutionalized principles, structures, and processes for administering to projects. Being considerably different from project management, project governance details, in its entirety, all the processes and actors involved in the project delivery process spanning across multiple scales and not just the project environment [20]. As such, it facilitates the linking of strategic objectives behind the project and the actual implementation of these objectives at the project level through the efficacy of the structures and alignment of actors. These structures and processes include contracts between actors, defined procurement strategy and pathways, risk allocation and management, monitoring and coordination of work during various phases of the project lifecycle, processes for collaboration among project stakeholders, and the nature of communication between actors [21].

The procurement and delivery of infrastructure assets is a complex undertaking. Its complexity is heightened by the multiplicity of parties involved, as well as the time and cost constraints within which it must be delivered. Also, the socio-economic and environmental implication of its failure is one that is rather imagined than witnessed. This makes the institution of effective governance and management frameworks imperative. An infrastructure delivery (ID) system is described as a representation of all types of interorganizational and multi-layered relationships between various project actors during the delivery of the infrastructure asset, as well as the tendencies these parties bring upon the project [22].

It was reiterated that the aim of a governance framework includes the attainment of the strategic objectives upon which the initiation of the project was predicated [23]. Recently, infrastructure client organizations (ICOs) are increasingly committing to sustainable procurement and delivery of projects. Suddenly, ICOs are tasking their ID systems to conform to and deliver projects according to sustainable development (SD) tenets. Such requests are intended to boost the ICO's pro-sustainability reputation whilst supporting competitiveness in the marketplace. Obviously, the adoption and utilization of the appropriate governance framework will assist ID systems to deliver on this mandate. Yet, a cursory look across the globe reveals that projects are still being delivered in a manner akin to business as usual. This is especially the case in developing countries like Nigeria and South Africa where the need for new infrastructure is paramount. Scholars attributed this observation to the inability of the extant governance approaches to deliver on SD mandates, and they solicited for the incorporation of SD tenet into these governance frameworks or perhaps the development of new sustainability 
governance frameworks for ID systems as a probable panacea. Corroborating these scholars, [24] insist that the ability of a project to deliver on sustainability outcomes is largely dependent on the mode of governance adopted. However, [25] assert the absence of an appropriate governance framework for governing sustainability in projects and society. This makes the study of sustainability governance from the perspective of ID systems imperative.

The concept of sustainability governance defies a widely accepted definition in the literature. However, [17] presents a most succinct definition which is appropriate for this study's context. The authors present sustainability governance as an assemblage of formal or informal networks existing between actors and the systems within which these networks are domiciled, which affect sustainability through the integration of various dimensions, culminating in the integration of distinct knowledge bases, as well as multi-actor perspectives. Such integration enables the attainment of a consensus on what SD dimensions to prioritize across the project lifecycle. However, the absence of such a governance framework stands to negate sustainable project delivery and, even more so, the working of ID systems. In reiterating the need for such frameworks to be designed and applied, [26] outline various factors for the actualization of these frameworks. These factors include internalization of external costs, integration of policy considerations within the delivery system, development of common and shared SD objectives, selection of suitable sustainability-based criteria for planning, and widely accepted indicators for measuring actionable progress toward sustainability, agreement concerning trade-offs, provision of information concerning available incentives for practical implementation, and development of programs for continuous system innovation. For effective sustainability governance to be entrenched in construction project delivery systems such as ID systems, certain features such as effective partnerships within networked systems, imbued with significant degrees of reflexivity, participation, adaptability, and social learning processes, as well as knowledge integration and multi-actor management, appear imperative [20]. Yet, conceptualizing systems with these characteristics requires an understanding of success factors which will facilitate smooth adoption and implementation, thereby fostering effective sustainability governance therein. This is what this study seeks to achieve through an identification of the success factors required for the design and development of workable sustainability governance implementation frameworks for ID systems from the perspectives of the relevant parties working within the context.

\subsection{The Viable Infrastructure Delivery Systems Model (VIDM)}

The viable infrastructure delivery systems model (VIDM) is a toolkit for the appraising and/or diagnosis of the ability of ID systems to attain and maintain viability [22]. Viability is described as an organizational attribute which enables organizations to adapt to their selected environment or, better still, adapt their environment to suit their internal structures [27]. In the case of ID systems, viability would imply the system's ability to deliver an infrastructure project in a sustainable manner despite external and internal challenges [22]. Additionally, the VIDM enables a proper conceptualization of inter-organizational relationships existing within the ID system, as well as the responsibilities of the actors within the conceptualized model. Derived from the viable systems model (VSM) and its underlining principles, the VIDM provides a structured methodology for deciphering the ability of the governance structure in an ID system to deliver on SD mandates. Its ability to perform this diagnosis is premised on an establishment of the presence of six related functions within the ID system. These functions are as follows: operation, coordination, control, monitoring, intelligence, and policy, respectively. The presence of these factors remains imperative for enabling effective sustainability governance.

Figure 1 shows a typical VIDM for an ID system during and at the end of the project delivery cycle.

However, in the VIDM, these subsystems are appropriately named to reflect the governance structure present within ID systems. This information is provided in Table 1.

As observed from Table 1 and Figure 1, the VIDM's metasystem (the bounded area with thick borders) happens to be responsible for the following tasks: project conceptualization, initiation, 
control and monitoring, and some aspects of the project coordination and implementation. This confirms the significant position wielded by the ICO in enabling project governance and, by extension, project success.

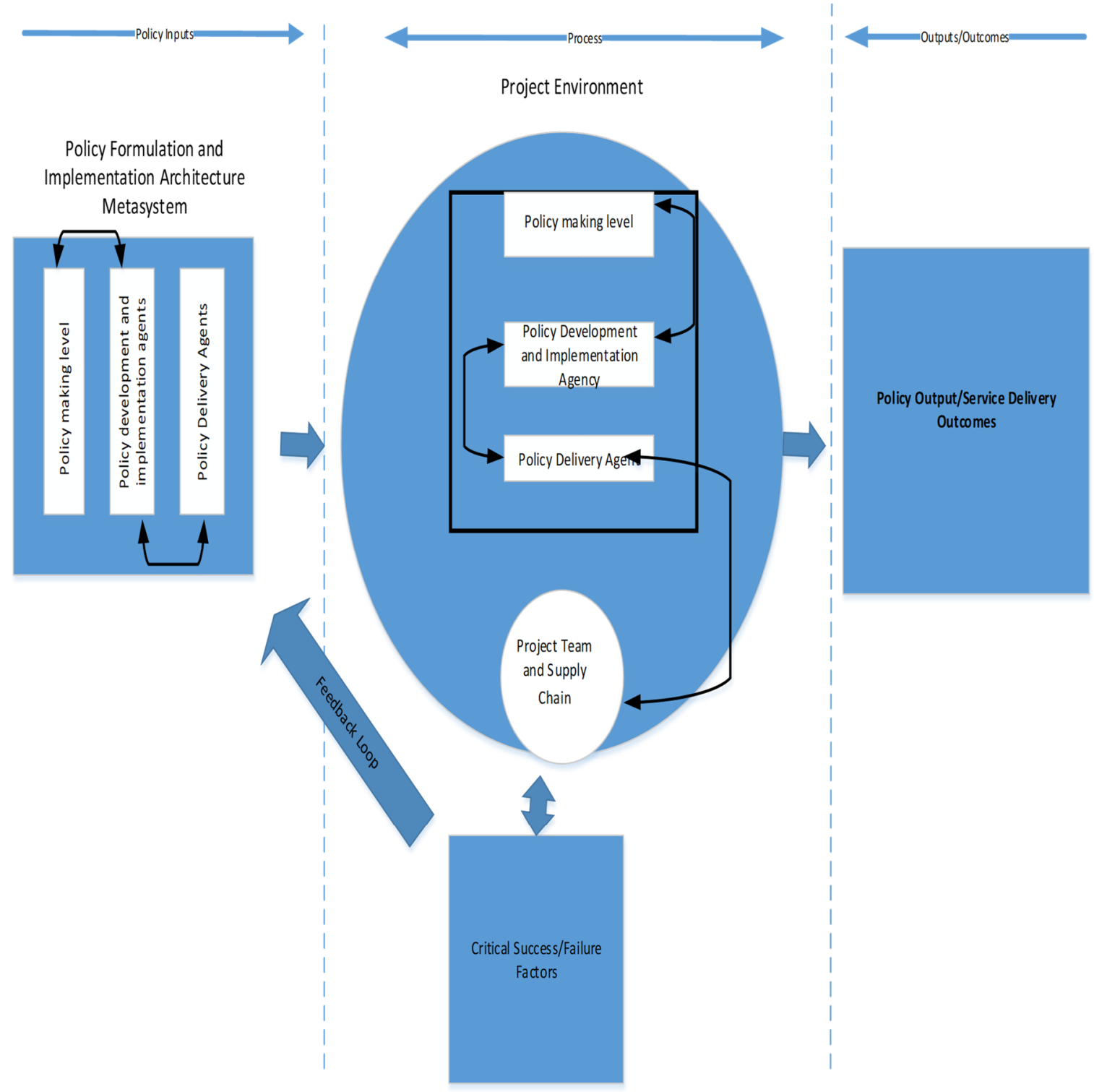

Figure 1. A typical viable infrastructure delivery systems model (VIDM) (Awuzie and McDermott, 2019).

Table 1. Comparison of terms used in the viable systems model (VSM) and viable infrastructure delivery systems model (VIDM).

\begin{tabular}{ccc}
\hline Subsystem & VSM & VIDM \\
\hline 5 & Policy & Policy-making level (enabling government policy) \\
4 & Intelligence & Policy development, implementation, and regulatory agencies \\
$33^{*}$ & Control/monitoring & Project departments (infrastructure client organization) \\
2 & Coordination & Contractor/project management department (infrastructure client organization) \\
1 & Operations & Project environment (project team and supply chain) \\
\hline
\end{tabular}

Source Awuzie and Mc Dermott 2019; 3 *-monitoring.

Figure 1 attests to the complexity of ID system due to the various organizations that are involved with the delivery process. Such complexity tends to negate attempts at embedding SD tenet into the processes inherent in the ID system. Also, policy initiatives leading to the conceptualization of 
these infrastructure projects and the associated SD deliverables tend to be lost in this complexity and, hence, not being considered and/or implemented at the project level. This was described as a salient contributor to the rising levels of ICO dissatisfaction being experienced concerning the functionality of delivered projects and the ability of these projects to achieve the original goals; this was labeled as a policy or strategy disjuncture [28]. Also, a lot of SD aspects are difficult to measure, especially during infrastructure delivery, and ICOs only have to wait to the end of the delivery period and commissioning to appraise the deliverables. This poses a challenge for these ICOs, as considerable investments would have been made in the projects for the purpose of achieving these SD aspects in the first instance. The VIDM where succinctly deployed enables a conceptualization of the relationships existing between various stakeholders, highlighting their responsibilities and the communication channels between them. Such conceptualization stimulates effective governance of the ID system, thus allowing for traceability and accountability in the system as it concerns implementation of SD tenet during the delivery period.

Based on the above, the utility of the VIDM in facilitating effective governance can be deduced. However, the VIDM is just a toolkit and can be modified to serve different governance-related deliverables. As such, when developing a VIDM to facilitate sustainability governance in an ID system, there is need to identify the critical success factors influencing the toolkit design. Previous studies explored the failure and success factors affecting the implementation of the socio-economic policy (as well as other policies) objectives through ID systems [29]. However, this study seeks to identify the critical success factors for designing VIDMs to prompt effective sustainability governance of ID systems.

\section{Research Method}

This study adopts a qualitative multi-case study research design. The choice of this design was based on its usefulness for carrying out an in-depth study into a phenomenon within its natural environment. Scholars like [30,31] reiterated the suitability of the case study research design for conducting research within organizations. The ID system doubles as an organization albeit a temporary multi-organization [32,33]. Of importance to the authors during the selection of a research design was the ability to deploy a plethora of tools for data elicitation and analysis. In this regard, the case study's capability is renowned [34]. Accordingly, data were collected through a mix of semi-structured interviews and project documents analysis.

The case selection criteria were designed to allow for analytical generalization of the study's findings. The principles of replication (theoretical and literal) logic were applied during the selection of cases [34]. Taking the above into consideration, the selection criteria for case selection were narrowed to three: the ID system being selected must be active, i.e., either presently involved in the delivery of infrastructure or recently disbanded following the completion of an infrastructure project; the infrastructure project must comprise civil works, i.e., roads, buildings, storm water drainages, etc.; finally, the business cases for the project must outline the embedding of aspects of SD tenet as part of the program or project deliverable. In addition to this, the effort was made to ensure variance in project size in some ways to enable replication. The authors got access to the ID systems through the ICOs. Indeed, this proved beneficial as it enabled access to members of the supply chain. Also, the authors had a list of projects to choose from. The rationale behind the choice of recently completed projects was to allow for access to representatives of participating organizations who moved on upon project completion. Furthermore, the VIDM provided the authors with the platform for mapping these representatives turned interviewees on its subsystems. The ID system as presented through the VIDM served as the study's unit of analysis. A brief background of the case characteristics is provided in Tables 2 and 3. 
Table 2. ICO—infrastructure client organization; SD—sustainable development.

\begin{tabular}{cccc}
\hline Case Study Characteristics & Case Study 1 & Case Study 2 & Case Study 3 \\
\hline Country & Nigeria & Nigeria & Nigeria \\
Sector & Transportation & Education (School Building) & Education (School Building) \\
Value & $>1 \mathrm{~b}$ & $<1 \mathrm{~b}$ & $>1 \mathrm{~b}$ \\
Ownership of ICO & Public & Public & Private \\
Status & Ongoing (70\% Completed) & Recently completed (February 2019) & Recently completed (October 2018) \\
Mandate for SD deliverables & Yes & Yes & Yes \\
\hline & \multicolumn{2}{c}{ Source: Author's fieldwork (2019). }
\end{tabular}

Table 3. ICO—infrastructure client organization; SD—sustainable development.

\begin{tabular}{cccc}
\hline Case Study Characteristics & Case Study $\mathbf{4}$ & Case Study $\mathbf{5}$ & Case Study $\mathbf{6}$ \\
\hline Country & South Africa & South Africa & South Africa \\
Sector & Health (Hospital) & Education (School Building) & Education (School Building) \\
Value & $>1 \mathrm{~b}$ & $<1 \mathrm{~b}$ & $>1 \mathrm{~b}$ \\
Ownership of ICO & Public & Public & Private \\
Status & Completed (June 2018) & Completed (November 2018) & Completed (February 2019) \\
Mandate for SD deliverables & Yes & Yes & Yes \\
\hline
\end{tabular}

Source: Authors' fieldwork (2019).

Based on the information in Tables 2 and 3, it can be seen that three case studies were sourced from different economic sectors and belonged to different value bands. Also, the projects selected had mandates for SD deliverables. However, it is pertinent to note that the study being reported in this paper forms part of an ongoing wider study. As such, the six cases reported here form part of 12 case studies selected from four sub-Saharan African countries: Nigeria, Angola, South Africa, and Ghana. It is expected that the findings from the broader study will be validated against the propositions raised in [23] concerning the nuances in construction project governance in developing and developed countries through a survey with stakeholders in the developed country context. These propositions pertained to the contribution of the various governance aspects to the attainment of sustainable delivery systems within the construction and infrastructure sector of developing countries. These aspects consist of the following: the nature of the relationships within the delivery system based on formal and informal structuring, and the degree of collaboration among participants in the ID system to engender sustainable project delivery. In that study by [23], it was held that the geo-political context (developing vs. developed country context) had an implication on the success of construction project governance or otherwise.

In addition to enabling a validation of these previously mentioned propositions, the broader study also seeks to facilitate the development of a context-specific sustainability governance implementation framework for ID systems in developing countries. However, in this particular study, emphasis is placed on exploring the influence of any or a combination of any of the following features on the conceptualization/design of an effective sustainability governance implementation framework for ID systems situated in developing countries:

1. The institutional and regulatory arrangements associated with distinct economic sectors;

2. Nature of ownership (public, private, or public-private);

3. Country-specific conditions;

4. The value of the project being delivered.

It is expected that an understanding of the influence on these features will enable the identification of a generic list of success factors for the design of effective sustainability governance implementation frameworks in developing countries. This is the contribution which this study seeks to make, albeit enabled by the VIDM. The case selection criteria adopted in this study were allowed for a selection of case studies from different economic sectors and different value bands to allow a validation of this proposition.

Tables 4 and 5 provides information concerning the cases and the number of interviewees per case according to the VIDM's subsystems. In total, 48 interviews were conducted over a nine-month period. 
Table 4. Interviewees Nigeria.

\begin{tabular}{cccc}
\hline VIDM Subsystem & Number of Interviewees (Case 1) & Number of Interviewees (Case 2) & Number of Interviewees (Case 3) \\
\hline 5 & Policy document & Policy document & Policy document \\
4 & 3 & 1 & 1 \\
$3 / 3^{*}$ & 1 & 1 & 2 \\
2 & 1 & 3 & 1 \\
1 & 2 & 3 & 2 \\
Total & 7 & 8 & 6 \\
\hline \multicolumn{4}{c}{}
\end{tabular}

Table 5. Interviewees South Africa.

\begin{tabular}{cccc}
\hline VIDM Subsystem & Number of Interviewees (Case 4) & Number of Interviewees (Case 5) & Number of Interviewees (Case 6) \\
\hline 5 & Policy document & Policy document & Policy document \\
4 & 2 & 2 & 2 \\
$3 / 3^{*}$ & 2 & 3 & 2 \\
2 & 2 & 2 & 3 \\
1 & 3 & 2 & 2 \\
Total & 9 & 9 & 9 \\
\hline
\end{tabular}

Source: Authors' fieldwork (2019). 3 *-monitoring.

Access to the ID systems serving as case studies on this project was gained through prior correspondence with the directors in charge of infrastructure projects. These public sector officials were informed of the significance of the study, especially as it concerned the incorporation of SD tenets in delivery systems and the benefits thereof. The semi-structured interviews were conducted at different intervals between June 2018 and March 2019 at the offices of the various organizations and on Skype. The interview sessions lasted for an average of $40 \mathrm{~min}$ and were tape-recorded with the permission of the interviewees. The interviewees were sent a note, two weeks prior to the scheduled interview sessions, providing a detailed background of the sustainability governance of the ID systems concept. The two-week window availed those who were unsure to seek further clarification from the first author through informal chats. During this process, a reduction in the number of prospective interviewees was observed. As such, only those who indicated an appreciable level of understanding of the concept showed interest in continuing with the sessions.

Questions asked during the interview sessions ranged from the understanding of the concept of sustainability and SD, the level of satisfaction of clients concerning the delivered asset from a sustainability/sustainable development goals perspective, understanding of project governance and the distinction between governance and management, an identification of project-based activities with potentials to deter attainment of sustainability on projects, knowledge of the 3P (portfolio, program, and project), and the nexus thereof. Also, of interest to the interviewer was the interviewees' understanding of strategy and their experiences of project-level implementation of strategy/policy, particularly SD-related strategy/policy. Discussions around these aspects provided robust data sets from the sessions. These questions allowed for the elicitation of the level of understanding held by members of the ID system concerning their perception of the ability of the informal and formal governance structure within the ID system to engender sustainability governance, as well as their respective roles in fostering this. The first author acted as an interviewer for the reported cases, whereas both authors independently reviewed the transcripts and met at intervals to discuss the outcomes of their individual interpretation of the data. This sense making process [35] happens to be ongoing. Copies of relevant SD-related policies upon which the projects were premised were obtained and studied. The emergent data were subsequently analyzed using a variant of qualitative content analysis (QCA). The themes were not predetermined but allowed to emerge from the datasets. The authors understood the concept of sustainability governance, ID systems, and success factors, and they deployed this understanding in making sense of the data, thereby culminating in the success factors identified in the subsequent section. 


\section{Discussion of Findings}

In this section, a presentation and discussion of preliminary findings from the studied cases follow. However, the findings are not structured according to the case but rather in line with the success factors identified. The findings are structured according to two main themes: level of infrastructure client organization (ICO) satisfaction with the delivered asset, and the success factors for designing sustainability governance into ID systems.

\subsection{Level of ICO Satisfaction}

Client dissatisfaction with the delivered infrastructure asset remains topical within the realm of construction project management and governance [36-38]. Often, the project team is fixated on the attainment of project management success and not project success. This often leads to the incidence of projects which meet the success criteria for time, cost, and quality (according to the specifications), whilst failing to support the actual objective that led to its commissioning in the first place. This challenge is exacerbated with the increasing advocacy for ICOs to contribute toward the actualization of the sustainability agenda through their project development initiatives. Scholars agree that the operationalization of SD dimensions through projects remains a confusing territory [14,15], especially the social SD aspects $[39,40]$. The ICO representatives across the three case studies were asked if the projects being delivered had mandates for implementation of SD-related mandates during the project delivery lifecycle. All the relevant interviewees answered in the affirmative, citing instances of a modification of the pre-qualification documents and tender documents to cater to the achievement of such mandates. These mandates were mostly concerned with the engagement of local labor, use of labor-intensive approaches for construction, and upskilling of the artisans on facets like bookkeeping and basic accounting practices. Also mentioned was the patronage of local suppliers and locally available goods, responsible sourcing, adoption of environmentally friendly activities during delivery, and resource efficiency. This information is not new given the plethora of literature concerning targeted procurement, local content development, social value, etc. [41,42]. Although, such mandates are replete within both developing country and developed country contexts; in the former, they seem to align with socio-economic SD dimensions, unlike in the latter where the environmental SD dimension was gaining an upper hand until recently.

Upon this confirmation of the existence of such mandates, in addition to the usual project success criteria of time, cost, quality, and functionality, the interviewer sought to determine the level of satisfaction possessed by the representatives of the ICOs as it concerned the ability of the ID system to achieve these SD mandates. Interviewees from the ICOs involved with Case 1 and 3 expressed a "below average" degree of satisfaction, whereas the representative from the ICO for Case 2 posted an above average score. The response obtained provided the platform for appraising the cases with the VIDM to stimulate the success factors for designing for sustainability governance in ID systems. This is based on a proposition that ID systems which are designed to facilitate effective sustainability governance prompt the implementation of SD-based mandates during delivery.

\subsection{Success Factors}

The term "success factors" gained prominence in the project management and governance domain since the early works of Pinto and Slevin [43]. These scholars attribute the salience of success factors to the increasing need for project managers and relevant stakeholders to manage, appraise, and report on project performance. In this regard, project success factors and project success criteria are utilized. Although a clear distinction between success factors and success criteria is provided therein, this study is concerned with the former, which is described as comprising a set of distinct elements which, when influenced, are able to increase the likelihood of the project/activity being successful [43] (p. 758). In this study, success factors for designing sustainability governance into ID systems comprise various elements or sets of elements which are likely to increase the likelihood of 
producing successful incorporation of SD tenet into the governance apparatus of the delivery system. Expectedly, such successful incorporation will lead to the implementation of sustainability initiatives during the procurement and delivery phases of the infrastructure project.

Whereas a plethora of success factors were identified so far, this study, for brevity's sake, provides discussions on some of these factors.

\subsubsection{Presence of the Six Subsystems of the VIDM}

Based on the tenets of philosophies underpinning the VIDM, the viable systems model (VSM), and theory of systems viability, the presence of six subsystems within the VIDM/VSM remains mandatory for the attainment of viability. Viability in this regard refers to a critical organizational (temporary multi-organizational) attribute which infers an organization's ability to go beyond merely performing its functions but posting successful performance [28]. Based on the law of requisite variety, systems viability allows a system to remain viable, delivering on its purpose whilst maintaining its identity without undue influence from its environment [44]. Suffice it to state that the organizations are only able to implement the set objectives (like SD tenet) optimally if they can attain and maintain viability.

Proponents of systems viability opine that the presence of the subsystems mentioned in Table 1 within an organization will enable that organization to become viable. Transposed to the ID system project environment, these subsystems comprise policy/strategy documents, organizations, departments, and individuals carrying out the functions allocated to these subsystems and the composition of their internal structures in the case of organizations and departments. Based on the need to ensure compliance with the principle of recursivity (see [45]), an understanding of the internal structures of the implementing organizations and/or department, as well as the regulatory agencies, becomes imperative.

In the cases understudied, the interviewer had to conceptualize the entire ID system from the perspectives expressed by the interviewees within each case. Then, the authors reviewed the emergent vignette to decipher the responsibilities of the various organizations operating within the ID system and the extant interorganizational interfaces for instances of collaboration or otherwise. Following from the review, it was observed that Cases 1,5, and 3 did not possess a comprehensive representation of the required subsystems. For instance, in case 3 , there was no policy/strategy document or resolution of the board of the institution stipulating the SD-related mandates as expected deliverables. In Case 1, whereas the mandates were explicitly stated in government policy, the implementing agency prioritized cost-cutting measures through upholding the lowest and most responsive tenders against the value proposition of empowering the local economy. However, in Cases 2, 4, and 6, the mandates were clearly spelt out during the procurement process and monitored during the project implementation process proper. In designing for sustainability governance in ID systems, there is need to ensure that the various organizations are made to be aware of their responsibilities concerning the implementation of any SD-related mandates that are expected of the ID system. This will allow for transparency in the manner that trade-offs are arrived at between various facets of the mandate. In addition, interviewees were unanimous on the need to allow for early engagement and involvement of the project stakeholders. They argued that this will provide a platform for the development of a common ontology as it concerns the significance of the project in the implementation of the SD-related mandate. When this is done properly, an ID system stands a better chance of delivering on SD-related benefits through the instrumentality of effective sustainability governance.

\subsubsection{Definition of ID System's Purpose through Established Communication Channels}

A proper definition of the ID system's purpose is imperative at the early stages. Scholars opine that a system's purpose is what it does or what it is/was set up to do [44]. Impliedly, ICOs should clearly articulate the purpose of the ID system at the commencement of the project. Such an articulation will assist relevant stakeholders to understand what facets to prioritize above others. Across the six cases examined, the purpose of the ID system was not clearly articulated. When the interviewer 
sought to establish the perception of the interviewees concerning the purpose of their ID systems, all interviewees identified the delivery of the physical asset and time, to the approved budget and in accordance with the specifications as the purpose of their respective ID systems. No mention was made of the SD-related deliverables by any of the interviewees. This implies that the communication of the policy/strategy initiatives which necessitated the project's commissioning was not performed in an appropriate manner. As such, relevant parties will be concerned with the delivery of the project to the previously mentioned parameters. Also, they will be unwilling to make concessions for the incorporation of any SD deliverables which they opine may lead to cost escalation. Therefore, the establishment of clear and concise communication pathways within the ID system remains another salient success factor for designing effective sustainability governance in infrastructure projects.

\section{Conclusions}

This study sought to identify the success factors required for the design and development of workable sustainability governance frameworks of infrastructure delivery systems. It is quite clear that ICOs are fostering the inclusion of SD deliverables through the projects being undertaken but lack the proper monitoring and control for achieving the desired outcomes. Evidence from the case studies highlights the continuous business as usual by project team members of measuring success of projects based on time, cost, and quality, while they pay diminutive attention SD as a parameter for project success. Moreover, ICOs do not have the complete subsystems mentioned in Table 1 to assist them with proper planning of achieving the SD in infrastructure projects; hence, the VIDM proves to be an imperative framework. SD deliverables seem to be missed right from the commencement of the projects; secondly, the outcomes are only measured after the projects are completed. The VIDM provides an opportunity to measure the outcome of SD deliverables in the realm of the entire life cycle of the project.

Success factors identified from the findings include a detailed definition of the ID outlined right from the beginning of the project with all project stakeholders present. Secondly, early involvement of the project stakeholders proved to be imperative for project success as mentioned by respondents. $\mathrm{SD}$ as an outcome is proving to be complicated for project teams to implement due to the continuous iron triangle of project management success factors being the only measurement of performance of ID systems. A proper policy/strategy on SD is imperative to communicate with all stakeholders of the ID systems in order to cascade that to implementation phases of the projects. A clear and concise communication pathway is key to achieving SD deliverables on ID systems. From the study's findings, it is evident that the success factors identified were not peculiar to any category of case studies. Accordingly, it can be deduced that the geo-political/context-based variables/features identified in the study as possessing the potential to influence the conceptualization and/or design of effective sustainability governance implementation frameworks in ID systems in developing countries do not actually affect the nature of success factors.

Author Contributions: B.A.: conceptualized the paper, collected data in Nigeria, partly written the paper. T.G.M.-Co-conceptualized the paper, collected data in South Africa, and written paper in part and proof reading. All authors have read and agreed to the published version of the manuscript.

Funding: This research received no external funding.

Conflicts of Interest: No conflict of interest is reported by the authors.

\section{References}

1. Swilling, M. Sustainability and infrastructure planning in South Africa: A Cape Town case study. Environ. Urban. 2006, 18, 23-50. [CrossRef]

2. Vives, A.; Benavides, J.; Paris, A.M. Selecting infrastructure delivery modalities: No time for ideology or semantics. J. Constr. Eng. Manag. 2009, 136, 412-418. [CrossRef] 
3. Willetts, R.; Burdon, J.; Glass, J.; Frost, M.W. Fostering sustainability in infrastructure development schemes. Proc. ICE Eng. Sustain. 2010, 163, 159-166. [CrossRef]

4. Esfahani, H.S.; Ramírez, M.A.T. Institutions, infrastructure, and economic growth. J. Dev. Econ. 2003, 70, 443-477. [CrossRef]

5. Shaw, G.; Walters, R.; Kumar, A.; Sprigg, A. Sustainability in infrastructure asset management. In Proceedings of the 7th World Congress on Engineering Asset Management (WCEAM 2012); Springer: Berlin, Germany, 2015; pp. 525-534.

6. Kibert, C.J. Sustainable Construction: Green Building Design and Delivery; John Wiley \& Sons: Hoboken, NJ, USA, 2016.

7. Sfakianaki, E. Resource-efficient construction: Rethinking construction towards sustainability. World J. Sci. Technol. Sustain. Dev. 2015, 12, 233-242. [CrossRef]

8. Tommelein, I.D. Journey toward lean construction: Pursuing a paradigm shift in the AEC industry. J. Constr. Eng. Manag. 2015, 141, 04015005. [CrossRef]

9. Babalola, O.; Ibem, E.O.; Ezema, I.C. Implementation of lean practices in the construction industry: A systematic review. Build. Environ. 2018, 148, 34-43. [CrossRef]

10. Nasir, M.H.A.; Genovese, A.; Acquaye, A.A.; Koh, S.; Yamoah, F. Comparing linear and circular supply chains: A case study from the construction industry. Int. J. Prod. Econ. 2017, 183, 443-457. [CrossRef]

11. Geissdoerfer, M.; Savaget, P.; Bocken, N.M.; Hultink, E.J. The Circular Economy-A new sustainability paradigm? J. Clean. Prod. 2017, 143, 757-768. [CrossRef]

12. Silvius, A.J. Sustainability in Project Management Processes. In Sustainability Integration for Effective Project Management; Silvius, G., Tharp, J., Eds.; IGI Global: Hershey, PA, USA, 2013.

13. Silvius, A.J.; Schipper, R.P.J. Sustainability in project management: A literature review and impact analysis. Soc. Bus. 2014, 4, 63-96. [CrossRef]

14. Banihashemi, S.; Hosseini, M.R.; Golizadeh, H.; Sankaran, S. Critical success factors (CSFs) for integration of sustainability into construction project management practices in developing countries. Int. J. Proj. Manag. 2017, 35, 1103-1119. [CrossRef]

15. Marcelino-Sádaba, S.; González-Jaen, L.F.; Pérez-Ezcurdia, A. Using project management as a way to sustainability. From a comprehensive review to a framework definition. J. Clean. Prod. 2015, 99, 1-16. [CrossRef]

16. Türke, R.-E. Governance: Systemic Foundation and Framework; Springer Science \& Business Media: Berlin, Germany, 2008.

17. Shiroyama, H.; Yarime, M.; Matsuo, M.; Schroeder, H.; Scholz, R.; Ulrich, A.E. Governance for sustainability: Knowledge integration and multi-actor dimensions in risk management. Sustain. Sci. 2012, 7, 45-55. [CrossRef]

18. Winch, G.M. Governing the project process: A conceptual framework. Constr. Manag. Econ. 2001, 19, 799-808. [CrossRef]

19. Cooke-Davies, T.J.; Crawford, L.H.; Lechler, T.G. Project management systems: Moving project management from an operational to a strategic discipline. Proj. Manag. J. 2009, 40, 110-123. [CrossRef]

20. Awuzie, B.; Ngowi, A. Towards a theory of sustainability governance in projects: An Exploratory study. In Proceedings of the 13 th International Conference on Organisation, Poreč, Croatia, 27-30 September 2017; Cerić, A., Huemann, M., Radujković, M., Vukomanović, M., Završki, I., Eds.; Croatian Association for Construction Management and University of Zagreb, Faculty of Civil Engineering: Zagreb, Croatia, 2017; pp. 616-625.

21. Ahola, T.; Ruuska, I.; Artto, K.; Kujala, J. What is project governance and what are its origins? Int. J. Proj. Manag. 2014, 32, 1321-1332. [CrossRef]

22. Awuzie, B.; Mcdermott, P. A conceptual model for evaluating infrastructure-based temporary multi-organisations. Built Environ. Proj. Asset Manag. 2015, 5, 103-120. [CrossRef]

23. Lizarralde, G.; Tomiyoshi, S.; Bourgault, M.; Malo, J.; Cardosi, G. Understanding differences in construction project governance between developed and developing countries. Constr. Manag. Econ. 2013, 31, 711-730. [CrossRef]

24. Ayre, G.; Callway, R. Governance for Sustainable Development: A Foundation for the Future; Earthscan: London, UK, 2013. 
25. Lange, P.; Driessen, P.P.; Sauer, A.; Bornemann, B.; Burger, P. Governing towards sustainability-Conceptualizing modes of governance. J. Environ. Policy Plan. 2013, 15, 403-425.

26. Kemp, R.; Parto, S.; Gibson, R.B. Governance for sustainable development: Moving from theory to practice. Int. J. Sustain. Dev. 2005, 8, 12-30. [CrossRef]

27. Hoverstadt, P. The Fractal Organization: Creating Sustainable Organizations with the Viable System Model; John Wiley \& Sons: Hoboken, NJ, USA, 2011.

28. Adham, K.A.; Kasimin, H.; Said, M.F.; Igel, B. Functions and inter-relationships of operating agencies in policy implementation from a viable system perspective. Syst. Pract. Action Res. 2012, 25, 149-170. [CrossRef]

29. Awuzie, B.O.; Mcdermott, P. Infrastructure Delivery Systems: Governance and Implementation Issues; Springer: Singapore, 2019.

30. Bryman, A. Research Methods and Organization Studies; Routledge: Abingdon, UK, 2003.

31. Hartley, J. Case study research. In Essential Guide to Qualitative Methods in Organizational Research; Sage: New York, NY, USA, 2004; Volume 1, pp. 323-333.

32. De Blois, M.; Lizarralde, G. A System of Classification of Temporary Multi-Organizations in the Building Sector. In Proceedings of the W092-Special Track 18th CIB World Building Congress, Salford, UK, 10-13 May 2010; p. 130.

33. De Blois, M.; Lizarralde, G.; De Coninck, P. Iterative Project Processes Within Temporary Multi-Organizations in Construction: The Self-, Eco-, Re-Organizing Projects. Proj. Manag. J. 2016, 47, 27-44. [CrossRef]

34. Yin, R.K. Case Study Research: Design and Methods; Sage Publications: Thousand Oaks, CA, USA, 2013.

35. Colville, I.; Brown, A.D.; Pye, A. Simplexity: Sensemaking, organizing and storytelling for our time. Hum. Relat. 2012, 65, 5-15. [CrossRef]

36. De Blois, M.; Herazo-Cueto, B.; Latunova, I.; Lizarralde, G. Relationships between construction clients and participants of the building industry: Structures and mechanisms of coordination and communication. Archit. Eng. Des. Manag. 2011, 7, 3-22. [CrossRef]

37. Loosemore, M.; Richard, J. Valuing innovation in construction and infrastructure: Getting clients past a lowest price mentality. Eng. Constr. Archit. Manag. 2015, 22, 38-53. [CrossRef]

38. Gan, X.; Zuo, J.; Ye, K.; Skitmore, M.; Xiong, B. Why sustainable construction? Why not? An owner's perspective. Habitat Int. 2015, 47,61-68. [CrossRef]

39. Sierra, L.A.; Pellicer, E.; Yepes, V. Social sustainability in the lifecycle of chilean public infrastructure. J. Constr. Eng. Manag. 2015, 142, 05015020. [CrossRef]

40. Herd-Smith, A.; Fewings, P. The Implementation of Social Sustainability in Regeneration Projects: Myth or Reality? 2008. Available online: http://www.rics.org/site/scripts/download_info.aspx (accessed on 26 April 2017).

41. Watermeyer, R. Linking developmental deliverables to public sector contracts. In Designing Public Procurement Policy in Developing Countries; Springer: Berlin, Germany, 2012.

42. Hawkins, J.; Wells, J. Modifying infrastructure procurement to enhance social development. In Proceedings of the Symposium on Sustainable and Value through Construction Procurement, CIB W092-Procurement System, Salford, UK, 29 November-2 December 2006.

43. Müller, R.; Jugdev, K. Critical success factors in projects: Pinto, Slevin, and Prescott-the elucidation of project success. Int. J. Manag. Proj. Bus. 2012, 5, 757-775. [CrossRef]

44. Schwaninger, M. Making change happen: Recollections of a systems professional. Kybernetes 2012, 41, 348-367. [CrossRef]

45. Schwaninger, M. Design for viable organizations: The diagnostic power of the viable system model. Kybernetes 2006, 35, 955-966. [CrossRef]

(C) 2020 by the authors. Licensee MDPI, Basel, Switzerland. This article is an open access article distributed under the terms and conditions of the Creative Commons Attribution (CC BY) license (http://creativecommons.org/licenses/by/4.0/). 